\title{
Mitochondrial haplogroup N1a phylogeography, with implication to the origin of European farmers
}

\author{
Malliya Gounder Palanichamy ${ }^{1,2^{*}}$, Cai-Ling Zhang ${ }^{1}$, Bikash Mitra ${ }^{1,3}$, Boris Malyarchuk ${ }^{4}$, Miroslava Derenko ${ }^{4}$, \\ Tapas Kumar Chaudhuri ${ }^{3}$, Ya-Ping Zhang ${ }^{1,2^{*}}$
}

\begin{abstract}
Background: Tracing the genetic origin of central European farmer N1a lineages can provide a unique opportunity to assess the patterns of the farming technology spread into central Europe in the human prehistory. Here, we have chosen twelve N1a samples from modern populations which are most similar with the farmer N1a types and performed the complete mitochondrial DNA genome sequencing analysis. To assess the genetic and phylogeographic relationship, we performed a detailed survey of modern published N1a types from Eurasian and African populations.

Results: The geographic origin and expansion of farmer lineages related N1a subclades have been deduced from combined analysis of 19 complete sequences with 166 N1a haplotypes. The phylogeographic analysis revealed that the central European farmer lineages have originated from different sources: from eastern Europe, local central Europe, and from the Near East via southern Europe.

Conclusions: The results obtained emphasize that the arrival of central European farmer lineages did not occur via a single demic diffusion event from the Near East at the onset of the Neolithic spread of agriculture into Europe. Indeed these results indicate that the Neolithic transition process was more complex in central Europe and possibly the farmer N1a lineages were a result of a 'leapfrog' colonization process.
\end{abstract}

\section{Background}

The emergence of farming in the Near East and its spread to Europe is one of the most significant processes in the evolutionary history of Europeans. The question of how agriculture spread into Europe and associated with the genesis of the genomes of modern Europeans has been a subject of debate and controversy among archaeologists, anthropologists, and geneticists. Some have argued that agriculture was introduced in large parts of Europe by rapid movement of immigrant farmers from the Near East [1]. Others have postulated the indigenous development of farming by hunter-gatherers and only minimal immigration from outside [2]. Recently researchers have taken steps to address this issue through direct comparison of ancient mitochondrial DNA (mtDNA) from European hunter-gatherers and early farmers $[3,4]$.

\footnotetext{
*Correspondence: empalani@yahoo.com; zhangyp1@263.net.cn 'Laboratory for Conservation and Utilization of Bio-resources, Yunnan University, 2 North Green Lake Street, Kunming 650091, China Full list of author information is available at the end of the article

Farming practices spread across Europe after the domestication of plants and animals in the Near East around 12,000 years ago. Archaeologists note that the spread of farming into central Europe was accompanied by Linear Pottery (Linearbandkeramik - LBK) and Alfödi Linear Pottery Culture (AVK). These early farming cultures are thought to have originated in Hungary and Slovakia about 7,500 years ago from where they spread rapidly as far as the Paris Basin and the Ukraine. To assess the Neolithic female contribution and associated farming spread into central Europe we performed a genetic study on the farmers skeletons remains from the LBK/AVK area. The first hypervariable segment (HV1) of the mtDNA control sequences information obtained from 24 out of 57 Neolithic skeletons from various LBK/AVK locations in Germany, Austria and Hungary belonged to typical western Eurasian haplogroups ( $\mathrm{H}$ or $\mathrm{V}, \mathrm{T}, \mathrm{K}, \mathrm{J}, \mathrm{U} 3$, and N1a). Among them, six of the farmers' skeletons had a distinctive and rare N1a mtDNA type. Furthermore, five of these six individuals display different N1a haplotypes and they were widespread in 
the LBK area. But today this N1a mtDNA type is very rare $(0.2 \%)$ in Europeans, suggesting that first Neolithic farmers did not have a strong impact on the genetic population structure of the modern European female lineages. Thus, this study result suggests that small pioneer farming groups carried farming into new areas of Europe and the surrounding hunter-gatherers adopted the new culture and then outnumbered the original farmers, diluting their N1a frequency to the low modern value [3].

However, previous studies did not address the question whether the mtDNA N1a-lineages of the skeletons belonged to immigrant farmers or originated from local Mesolithic peoples who adopted the farming [5]. Recently, researchers have presented important new data on this question by direct comparison of ancient mtDNAs from European hunter-gatherers and early farmer skeletons [4]. The most striking result of this study is that the mtDNA sequences of the early farmers were genetically distinct from the hunter-gatherers, thus confirming the hypothesis that the first farmers were not the descendants of local hunter-gatherers but immigrated into central Europe. Thus, it is concluded that outside colonizers brought farming to central Europe by a major migration event $[4,6]$. Furthermore, the craniometric data of the Mesolithic and Neolithic skull from Southwest Asia and Europe also suggest that the spread of farming into Europe was mainly due to the active dispersal of people from Southwest Asia [7].

Nevertheless, Rowley-Conwy [5] postulated the appearance of farming in Europe was not a demic "wave of advance" from the Near East, but rather a combination of small-step migrations, in which indigenously agriculturalised hunter-gatherers played an important role in the spread of farming in Europe. Further, he emphasized that the non-local mtDNA lineages of central Europe's earliest farmers most likely were of Greek, Balkan, or Black Sea hunter-gatherer descent rather than of the Near East origin. In addition, both central European farmer haplotypes and the N1a haplotypes found in the modern Europeans were not found in the Near East region, thus suggesting that the farmer N1a lineages may be indigenous to central Europe and less likely that they were originated from the Near East agriculturists [8]. To clarify the inconsistency on the farmers' origin and associated farming spread into central Europe, more detailed examination of farmers N1a lineages is required.

Our combined mtDNA-HV1 network analysis of farmer and modern N1a types reveals three phylogeographic branches- European, Central Asian, and African/ South Asian. The LKB farmer skeleton individualsDerenburg 1, 3 (DEB1 \& 3), Halberstadt 2 (HAL2), Flowborn 1 (FLO1), and Unterwiederstedt 5 (UWS5) types falls into the European N1a sub-branch. The AVK individual- Ecsegfalva 1 (ECS1) belongs to the Central Asian sub-branch. The African/South Asian branch is characterized by control region motif 16147G, which differs from the European and the Central Asian branches with the 16147A variant. However, a phylogeographic pattern based only on the HV1 sequence variation is insufficient to reveal the detailed genetic history of European farmers. On the contrary, the advance of complete mtDNA sequence analysis seems to be extremely useful for maternal phylogeny of farmer individuals reconstruction and thus may shed light on their origins and genetic history; furthermore, it helps to understand the movements of Neolithic communities across Europe in the past.

In order to reconstruct an unambiguous phylogeny of the farmer N1a types, 12 mtDNAs (from 2 Russia, 1 TatarRussia, 1 Kazakh- South Siberia, 1 Hungary, 1 France, 1 Italy, 2 India, and 3 European ancestry living in United States of America) were completely sequenced and compared with 7 previously published complete mtDNA N1a sequences. Our sampling strategy was based on the preliminary obtained data on HV1 sequence variation; in particularly samples closely related to the farmers' N1a haplotypes were chosen for complete mtDNA sequencing from the variety of modern populations (further details refer the materials and methods). Further, based on farmer lineage subclades information obtained, we have attempted to trace the possible areas of their origin by comparison with all available so far data from the European, Central Asian, Near Eastern, and South Asian populations as well as from the Caucasus.

\section{Results and Discussion}

A tree of the 19 complete mtDNA N1a sequences is presented in Figure 1, which includes also 7 previously published sequences. The phylogeny reveals an early split of African/Near East lineages with the HV1 region variant 16147G from the European and Central Asian lineages, which carry the 16147 A variant. In addition, later lineages share a coding region transition at nucleotide position (np) 3336, which allows the definition of subhaplogroup N1a1. Within the subhaplogroup N1a1, we noticed that the farmer samples - DEB1, ECS1 and other published sequences from Arabian Peninsula, Armenia, Egypt, and Setoland lacks the HV-1 mutation 16320. We sequenced a single mtDNA genome (sample 17 , figure 1) belonging to this group and the results have allowed us to rename N1a1 of Derenko et al. [9] as N1a1a. Now the revised phylogenetic tree points to 3336 and 16147A as the basal mutations for N1a1 subhaplogroup, whereas transition 16320 seems to be a characteristic mutation for a whole N1a1a. We have named the new haplotype sequence as N1a1b. Furthermore, previously established subgroup N1a1a defined by 


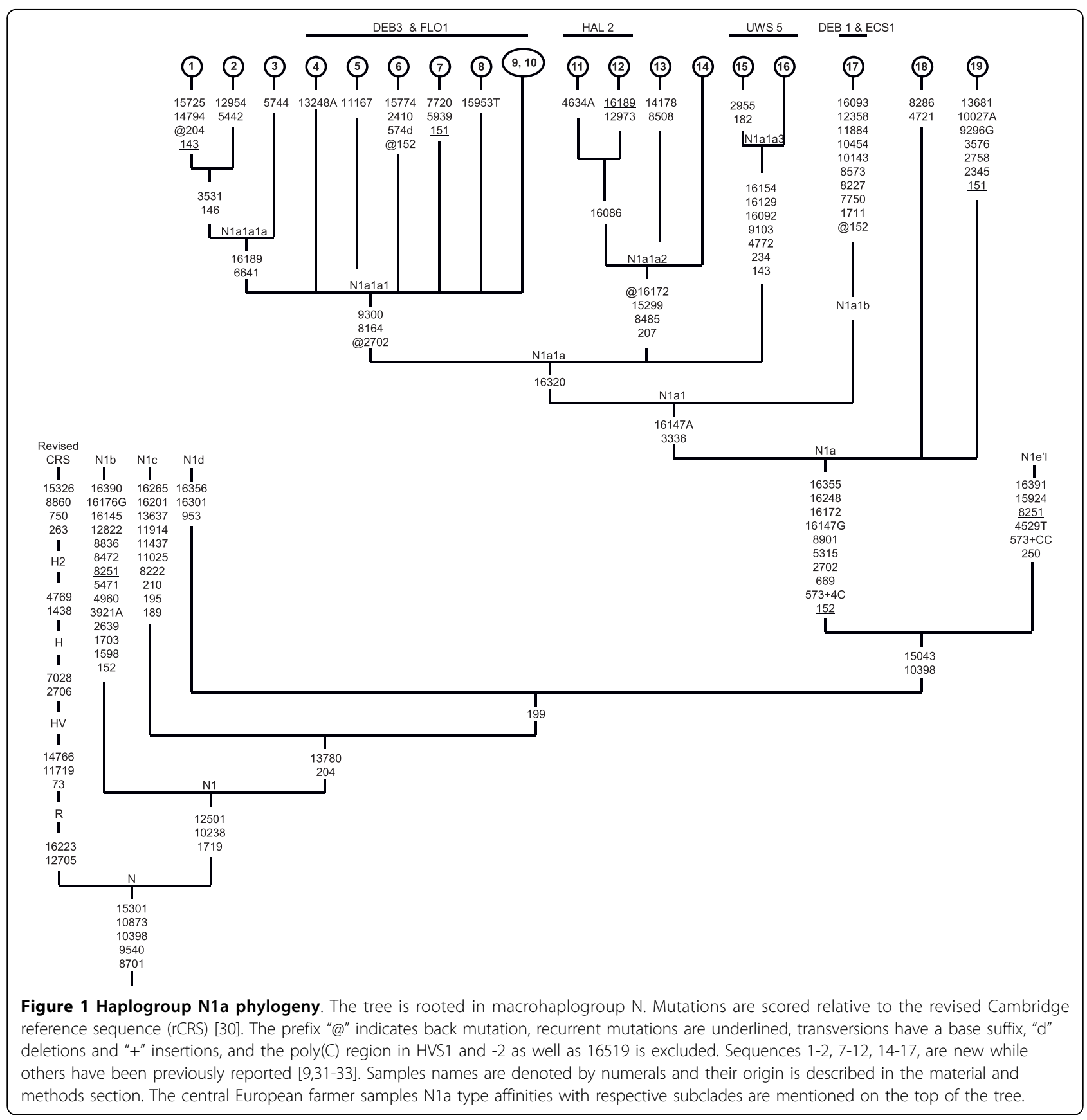

mutations 8164, 9300, and a back mutation 2702 were absent in the lineages 11 to 16 . This suggests that 2702, 8164 and 9300 are diagnostic mutations for one of the N1a1a subbranches which is named N1a1a1 here [10]. Finally, our new data identify two additional subclades that have not been reported earlier, these lineages are designated as N1a1a2 and N1a1a3 (Figure 1).

From our complete mtDNA sequences phylogeny, five different mtDNA haplotypes were observed within the central European farmers by Haak et al. [3] were classified into four subhaplogroups (Figure 1). The farmer samples DEB3 and FLO1 have an identical HV-1 motif 16147A-16172-16223-16248-16320-16355. The results of phylogenetic analysis of complete mtDNA sequences exactly matched to modern samples suggest that the farmer DEB3 and FLO1 lineages might belong to subhaplogroup N1a1a1. The exactly matched sequence with farmer HAL2 N1a haplotype (1608616147A-16172-16223-16248-16320-16355) was observed in modern Portuguese population from south Portugal. 
Nevertheless, in combination with specific HV-2 motif 152-199-204-207, a subset of closely related sequences was found in the modern populations and results of complete mtDNA sequencing of some of those samples (samples 11 and 12, Figure 1) unambiguously placed the farmer HAL2 lineage into subhaplogroup N1a1a2. Comparing the HV-1 motif of farmer sample UWS5 with the modern complete mtDNA sequence phylogeny (sample 15 and 16, figure 1) suggests that the farmer UWS5 lineage belong to subhaplogroup N1a1a3. Finally, farmer lineages DEB1 and ECS1 lacking the HV1 mutation 16320 belong to N1a1b branch.

In order to obtain a detailed picture of the central European farmers N1a lineage origin, we have performed a systematic phylogeographic survey by comparison of mtDNA sequences associated with farmer lineages with the published modern Eurasian data set and the results of this survey are reported in Table 1. As seen, mtDNA sequences of subcluster N1a1a1 related to the farmer DEB3 and FLO1 lineages are widely distributed, accounting for nearly half (82 out of 166) of the total N1a data (Table 1). Lineages from this subcluster were observed in populations of eastern/ central Europe, Volga-Ural region, central Asia, South Siberia, Egypt, Yemen, Iran, Turkey, and eastern/ southern India (Figure 2a) [3,9,11-16]. The cumulative frequency of N1a1a1 reaches a maximum in eastern Europe and central Asia, and decreases in the direction of central and northern Europe. The same occurs in the southern direction, towards Anatolia and the Caucasus. Furthermore, one of the N1a1a1 subclade, N1a1a1a, characterized by 16189 and 6641 in the HV1 and coding region is restricted to Kazakhstan, Altai and Buryat Republic, and European part of Russian Federation [3,9,14,16-19], and it shows significant heterogeneity $\left(\mathrm{n}=42 ; \chi^{2}=125.995 ;\right.$ d. f. $\left.81 ; \mathrm{p}<0.001\right)$ in the haplotype distribution, attesting that these areas were a center of expansion. The calculated expansion times of N1a1a1 and N1a1a1a were between 6,800 - 10,600 years (Table 2). Sequences from another N1a1a2 subcluster related to farmer HAL2 haplotype were observed in Denmark, Poland, Scotland, Norway, Switzerland, France, Portugal, Hungary, Austria, and Volga-Ural region [3,19-22] (Figure 2b). This subcluster shows a very young coalescence age between 3,400 - 4,000 years (Table 2). Overall, the observed phylogeographic distribution of farmer lineage related subclades N1a1a1 and N1a1a2 suggests that the ancient farmer sample DEB3, FLO1 and HAL2 may have been associated with local central and eastern European origin rather than with diffusion from Near East.

The farmer UWS5 lineage associated with subclade N1a1a3 which is widespread in Italy, Yemen, Arabian Peninsula, Austria, Germany, Slovakia, Sweden, and
Norway (Figure 2c) $[15,20,21]$. So, based on the current distribution of subcluster N1a1a3 haplotypes, it is rather difficult to establish the exact geographic origin of the farmer sample UWS5. Nevertheless, the preferential distribution of this haplotype in the Near East and central/ western Europe as well as its scarce observation in eastern Europe suggests that the lineage ancestral to UWS5 dispersed probably from the Near East through the southern Europe and then into central/western Europe. However, the clarification of the most likely place of origin of farmer UWS5 lineage requires further study. The farmer lineages ECS1 and DEB1 belong to sub-branch N1a1b which is found in the Arabian Peninsula, Armenia, and Italy $[3,14,20,23]$ (Figure $2 d$ ). Thus, the presence of this lineage in central Europe may represent a Near Eastern influence due to both a high frequency and a high degree of diversity of this lineage in the Arabian Peninsula.

The ancestral haplotypes to European N1a1 (haplotypes with $16147 \mathrm{G}$ ) are more common in the Arabian Peninsula, northern Africa [3,20,23-26], with a limited expansion around the Iran, Israel, Turkey, Greece $[13,19,27]$, and are relatively rare in Europe. The coalescence time for the whole N1a haplogroup based on synonymous mutations rates as well as coding region estimates was between 19,600-23,500 years (Table 2). Overall the distinct phylogeographic distribution of $\mathrm{N1a}$ subclusters and their coalescence times suggests that an initial diversification of N1a occurred in the Near East, followed by westwards dispersion of ancestors of particular subhaplogroup to southern Europe and northwards via Central Asian steppe zones to central Europe.

\section{Conclusions}

Based on the current N1a haplogroup phylogeny and phylogeographic information on the farmer mtDNA associated subclades distribution, we suppose that the farmer lineages-DEB3, FLO1, and HAL2 might be derived from local communities and that they would have adopted the farming culture indigenously. Therefore, the results of the present study are somewhat difficult to reconcile with the hypothesis that the N1a lineages were brought into central Europe by the Neolithic farmers from the Near East by a major demic diffusion event. Moreover, the evidence from phylogeographic analysis of N1a lineages emphasizes that European farmer N1a lineages might have been originated from different sources- from eastern Europe (for N1a1a1), from Near East via southern Europe (for N1a1b and perhaps for N1a1a3), and from local central European source (for N1a1a2). It is thus clear that Neolithic farmers' migration into central Europe did not occur in a uniform way; indeed these results indicate that the Neolithic transition process was more complex in central Europe and possibly the farmer N1a lineages were brought in through the 'leapfrog' colonization process $[5,28]$. 
Table 1 Distribution of mtDNA-N1a haplotypes

\begin{tabular}{|c|c|c|c|c|c|}
\hline Haplogroup & HVS-I(minus 16000) ${ }^{\mathrm{a}}$ & HVS-II $(73,263 \text { in addition })^{b}$ & $\mathrm{~N}$ & Sample origin & References $[3]^{\mathrm{c}}$ \\
\hline N1a & 147G-172-223-248 & & 1 & Turkey & [3] \\
\hline N1a & 147G-172-223-248-355 & & 1 & Yemen & {$[24]$} \\
\hline N1a & 147G-172-223-248-355 & & 5 & Ethiopia & [3] \\
\hline N1a & 147G-172-223-248-355 & & 2 & Tanzania & [3] \\
\hline N1a & 147G-172-223-248-355 & $151-199-204$ & 2 & Arabia Peninsula & {$[20]$} \\
\hline N1a & 147G-172-223-248-355 & $151-199-204$ & 1 & Saudi Arabia & {$[23]$} \\
\hline N1a & 147G-172-223-248-355 & 199-204 & 1 & Arabia Peninsula & {$[20]$} \\
\hline N1a & 147G-172-223-248-355 & 199-204 & 1 & Dubai-Arabia & {$[26]$} \\
\hline N1a & 147G-172-223-248-355 & 194-199-204 & 1 & Bedouin-Israel & {$[25]$} \\
\hline N1a & 147G-172-223-248-355 & $152-199-204$ & 1 & Greece & {$[27]$} \\
\hline $\mathrm{N} 1 \mathrm{a}$ & 147G-172-223-248-355 & $152-199-204$ & 1 & Russia & {$[19]$} \\
\hline N1a & 147G-172-223-224-248-355-357 & & 1 & Greece & [3] \\
\hline N1a & $147 G-172-223-248-260-355$ & & 1 & Ethiopia & [3] \\
\hline N1a & 147G-223-248-263-266-355 & & 2 & Yemen & {$[3]$} \\
\hline N1a & 147G-172-223-248-263-266-355 & & 1 & Yemen & {$[3]$} \\
\hline N1a & 147G-172-213-223-248-355 & & 1 & Somali & [3] \\
\hline N1a & 147G-172-213-223-248-291-355 & $146-152-182-185 C$ & 1 & Ethiopia & {$[25]$} \\
\hline N1a & 124-147G-172-213-223-248-355 & & 1 & Yemen & {$[3]$} \\
\hline N1a & 147G-172-223-248-295-355 & & 3 & India - South West & [3] \\
\hline N1a & 147G-172-209-223-248-295-355 & & 2 & India - South West & [3] \\
\hline N1a & 147G-172-223-248-295-297-355 & & 1 & Kabardian, North Caucasus & [3] \\
\hline N1a & 147G-172-223-248-295-297-344-355 & & 1 & Turkey & [3] \\
\hline N1a & 147G-172-223-248-295-344-355 & & 1 & Iran & {$[13]$} \\
\hline N1a1a1 & $172-223-248-320-355$ & & 1 & Lithunia & {$[14]$} \\
\hline N1a1a1 & $147 \mathrm{~A}-172-248-320-355$ & & 1 & Poland & {$[3]$} \\
\hline N1a1a1 & $147 A-172-223-248-320$ & & 1 & Estonia & {$[3]$} \\
\hline N1a1a1 & $147 A-172-223-248-320$ & & 1 & Tatar & [3] \\
\hline N1a1a1 & $147 A-172-223-248-320-355$ & & 2 & Yemen & [3] \\
\hline N1a1a1 & $147 A-172-223-248-320-355$ & & 1 & Turkmenistan & {$[3]$} \\
\hline N1a1a1 & $147 A-172-223-248-320-355$ & & 1 & Iran & [13] \\
\hline N1a1a1 & $147 A-172-223-248-320-355$ & & 1 & Kazakhstan & {$[16]$} \\
\hline N1a1a1 & $147 A-172-223-248-320-355$ & & 2 & Russia & [3] \\
\hline N1a1a1 & $147 A-172-223-248-320-355$ & & 1 & Estonia & {$[14]$} \\
\hline N1a1a1 & $147 \mathrm{~A}-172-223-248-320-355$ & & 5 & Estonia & [3] \\
\hline N1a1a1 & $147 A-172-223-248-320-355$ & & 1 & Lithunia & {$[14]$} \\
\hline N1a1a1 & $147 A-172-223-248-320-355$ & & 1 & Iran & {$[3]$} \\
\hline N1a1a1 & $147 A-172-223-248-320-355$ & & 1 & Slovakia & {$[3]$} \\
\hline N1a1a1 & $147 A-172-223-248-320-355$ & $152-199-204$ & 1 & Tatar-Russia & Present study (9) \\
\hline N1a1a1 & $147 A-172-223-248-320-355$ & $152-199-204$ & 1 & Russia & Present Study $(10$ \\
\hline N1a1a1 & $147 A-172-223-248-320-355$ & $152-199-204$ & 1 & Slovakia & {$[15]$} \\
\hline N1a1a1 & $147 A-172-223-248-320-355$ & $152-199-204$ & 1 & Altai Republic & [9] \\
\hline N1a1a1 & 147A-172-223-248-320-355 & $152-199-204$ & 3 & Finland & {$[14]$} \\
\hline N1a1a1 & $147 A-172-223-248-320-355$ & $152-199-204$ & 2 & India & Present study (8) \\
\hline N1a1a1 & $147 A-172-223-248-320-355$ & $151-152-199-204$ & 1 & India & Present study (7) \\
\hline N1a1a1 & $147 A-172-223-248-291-320-355$ & & 1 & Egypt & {$[3]$} \\
\hline N1a1a1 & $147 A-172-223-248-294-320-355$ & & 1 & Estonia & {$[3]$} \\
\hline N1a1a1 & 147A-172-223-248-294-320-355 & & 1 & India - South East & {$[3]$} \\
\hline N1a1a1 & 147A-172-223-248-295-320-355 & & 1 & Buryat Republic & {$[3]$} \\
\hline N1a1a1 & $147 A-172-209-223-248-320-355$ & & 2 & Croation-Italian & {$[3]$} \\
\hline N1a1a1 & $147 A-172-206-223-248-320-355$ & & 1 & France & [3] \\
\hline N1a1a1 & 147A-172-195-223-248-320-355 & & 1 & Germany & [3] \\
\hline
\end{tabular}


Table 1: Distribution of mtDNA-N1a haplotypes (Continued)

\begin{tabular}{|c|c|c|c|c|c|}
\hline N1a1a1 & 114A-147A-172-223-248-320-325-355 & & 1 & Germany & [3] \\
\hline N1a1a1 & 93-147A-169-172-193iC-223-248-320-355 & & 1 & Russia & [12] \\
\hline N1a1a1a & $147 A-189-223-248-272-320-355$ & & 1 & Russia & [3] \\
\hline N1a1ala & $147 A-172-189-223-248-320-355$ & & 1 & Russia & {$[17]$} \\
\hline N1a1a1a & $147 A-172-189-223-248-320-355$ & & 1 & Russia & [18] \\
\hline N1a1a1a & $147 A-172-189-223-248-320-355$ & & 5 & Kazakhstan & [16] \\
\hline N1a1a1a & $147 A-172-189-223-248-320-355$ & & 1 & Hungary & [3] \\
\hline N1a1a1a & 147A-172-189-223-248-320-355 & & 6 & Russia & [3] \\
\hline N1a1a1a & $147 A-172-189-223-248-320-355$ & & 3 & Altai Republic & [3] \\
\hline N1a1a1a & $147 A-172-189-223-248-320-355$ & & 1 & Kalmyks & [3] \\
\hline N1a1a1a & $147 A-172-189-223-248-320-355$ & & 5 & Kazakhs & [3] \\
\hline N1a1a1a & 147A-172-189-223-248-320-355 & & 3 & Turkey & [3] \\
\hline N1a1a1a & 147A-172-189-223-248-320-355 & & 1 & Hungary & [3] \\
\hline N1a1a1a & 147G-172-189-223-248-320-355 & & 1 & Altai Republic & [3] \\
\hline N1a1a1a & $147 \mathrm{~A}-172-189-223-248-270-320-355$ & & 1 & Lithunia & [14] \\
\hline N1a1a1a & $147 \mathrm{~A}-172-189-223-248-272-320-355$ & & 4 & Russia & [3] \\
\hline N1a1a1a & 147A-172-183C-189-223-248-320-355 & & 1 & Buryat Republic & [3] \\
\hline N1a1a1a & 147A-172-189-193iC-223-248-320-355 & $152-199-204$ & 1 & Poland & [19] \\
\hline N1a1a1a & 147A-172-189-193iC-223-248-320-355 & $152-199-204$ & 1 & Ulaanbaatar & [9] \\
\hline N1a1ala & 147A-172-189-193iC-223-248-320-355 & $152-199-204$ & 1 & Buryat Republic & [9] \\
\hline N1a1a1a & 147A-172-189-193iC-223-248-320-355 & 143-146-152-199 & 1 & Kazakh-South Siberia & Present study (1) \\
\hline N1a1a1a & 147A-172-189-193iCC-223-248-320-355 & $146-152-199-204$ & 1 & Hungary & Present study (2) \\
\hline N1a1a1a & 147A-172-187A-189-223-248-320-355 & & 1 & Russia & [3] \\
\hline N1a1a1a & $147 A-172-181-189-223-248-320-355$ & & 1 & Kazakhstan & [16] \\
\hline N1a1a2 & $147 A-223-248-320-355$ & & 1 & France & [3] \\
\hline N1a1a2 & $147 A-223-248-320-355$ & 152-199-204-207 & 1 & United States of America & Present Study (14) \\
\hline N1a1a2 & $147 \mathrm{~A}-172-223-248-320-355$ & 152-199-204-207 & 1 & Poland & {$[19]$} \\
\hline N1a1a2 & $86-147 A-223-320-355$ & & 1 & Switzerland & [3] \\
\hline N1a1a2 & $86-147 A-223-248-320-355$ & 152-199-204-207 & 1 & Arizona & Present Study (11) \\
\hline N1a1a2 & $86-147 A-223-248-320-355$ & & 3 & Switzerland & [3] \\
\hline N1a1a2 & $86-147 A-223-248-320-355$ & 152-199-204-207 & 1 & Austria & {$[21]$} \\
\hline N1a1a2 & 86-147A-189-223-248-320-355 & & 1 & Denmark & [3] \\
\hline N1a1a2 & 86-147A-189-193iCC-223-248-320-355 & 152-199-204-207 & 1 & France & Present Study (12) \\
\hline N1a1a2 & 86-147A-223-248-319-320-355 & & 1 & Scotland & [3] \\
\hline N1a1a2 & 86-147A-223-248-320-324-355 & & 1 & Acores-Portugal & [3] \\
\hline N1a1a2 & 86-147A-223-248-278-320-355 & & 6 & Russia & [3] \\
\hline N1a1a2 & 86-147A-223-248-278-320-355 & & 1 & Udmurts & [3] \\
\hline N1a1a2 & 86-147A-148-214-223-320-355 & & 1 & Norway & [3] \\
\hline N1a1a2 & 86-147A-172-223-248-320-355 & & 1 & Portugal & [22] \\
\hline N1a1a2 & 86-147A-172-223-248-320-325-355 & 152-199-204-207 & 1 & Arabia Peninsula & [20] \\
\hline N1a1a2 & 86-147A-164-172-223-248-320-355 & & 1 & France & {$[3]$} \\
\hline N1a1a2 & 86-147A-164-172-223-248-320-355 & & 1 & Portugal & {$[3]$} \\
\hline N1a1a2 & 86-147A-164-172-223-248-320-355 & & 1 & Hungary & [3] \\
\hline N1a1a2 & 86-147A-150-164-172-209-223-248-320-355-463 & 152-199-204-207 & 1 & New Mexico & Present Study \\
\hline N1a1a3 & $147 \mathrm{~A}-154-172-223-320-355$ & $152-199-204$ & 1 & Austria & {$[21]$} \\
\hline N1a1a3 & $147 \mathrm{~A}-154-172-223-320-355$ & & 1 & Sweden & [3] \\
\hline N1a1a3 & 147A-154-172-223-320-355 & & 1 & Slovakia & {$[3]$} \\
\hline N1a1a3 & $147 \mathrm{~A}-154-172-223-320-355$ & 152-199-203-204 & 1 & Slovakia & {$[15]$} \\
\hline N1a1a3 & $147 \mathrm{~A}-154-172-223-248-258-320-355$ & $152-199-204$ & 1 & Arabia Peninsula & {$[20]$} \\
\hline N1a1a3 & 147A-154-170-172-223-248-320-355 & & 2 & Yemen & [3] \\
\hline N1a1a3 & $92-129-147 A-154-172-223-248-320-355$ & 143-152-182-199-204-234 & 1 & South Carolina & Present Study (15) \\
\hline N1a1a3 & $92-129-147 A-154-172-223-248-320-355$ & 143-152-199-204-234 & 1 & Russia & Present Study (16) \\
\hline
\end{tabular}


Table 1: Distribution of mtDNA-N1a haplotypes (Continued)

\begin{tabular}{|c|c|c|c|c|c|}
\hline N1a1a3 & 92-129-147A-154-172-223-248-320-355 & & 1 & Molise-Italy & [3] \\
\hline N1a1a3 & 92-129-147A-154-172-223-248-320-355 & & 1 & Norway & [3] \\
\hline N1a1a3 & 92-129-147A-154-172-223-248-320-355 & & 1 & Germany & [3] \\
\hline N1a1b & $147 A-172-223-248-355$ & & 1 & Setoland & {$[14]$} \\
\hline N1a1b & $147 A-172-223-248-355$ & & 1 & Egypt & [3] \\
\hline N1a1b & 147A-172-223-248-355 & & 1 & Armenia & [3] \\
\hline N1a1b & $93-147 A-172-223-248-355$ & 199-204 & 1 & Italy & Present Study (17) \\
\hline N1a1b & $147 \mathrm{~A}-172-223-245-248-355$ & 183-199-204 & 1 & Arabia Peninsula & [20] \\
\hline N1a1b & 147A-172-189-223-248-355 & 199-204 & 1 & Arabia Peninsula & {$[20]$} \\
\hline N1a1b & 147A-172-223-248-266-274-355 & $199-204$ & 1 & Arabia Peninsula & {$[20]$} \\
\hline N1a1b & $147 \mathrm{~A}-172-218-223-248-261-274-355$ & 41-199-204 & 1 & Arabia Peninsula & {$[20]$} \\
\hline N1a1b & $147 A-172-218-223-248-261-274-355$ & 41-199-204 & 4 & Saudi Arabia & [23] \\
\hline
\end{tabular}

Mutations are scored relative to the rCRS [30]. Transversions and length variants ( $i=$ insertion) are specified.

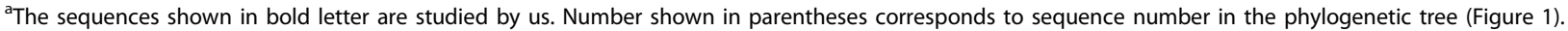

bength variation in the 303-309 and 311-315 C-stretch region is ignored.

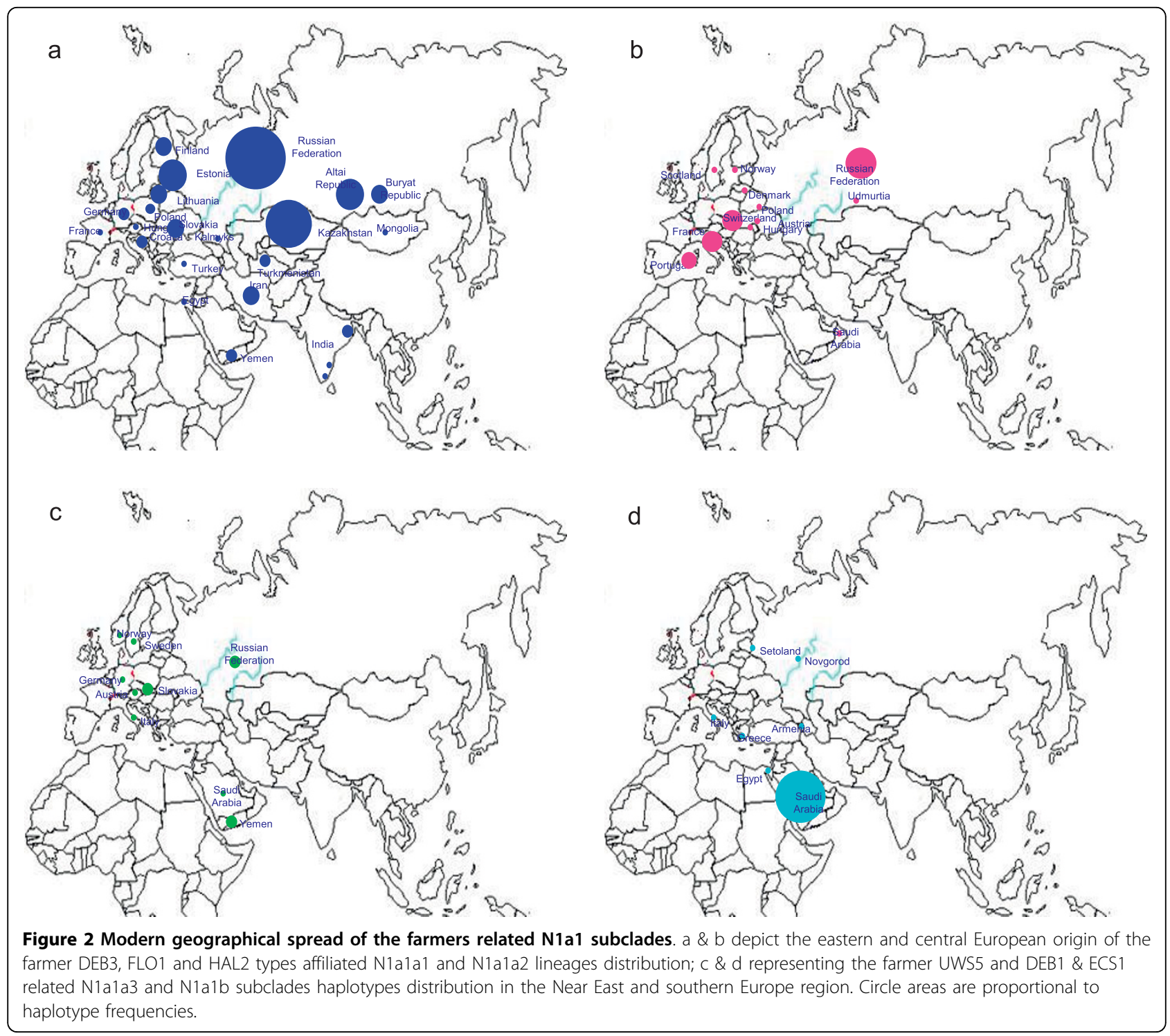


Table 2 Estimated ages (years) for different sub-clades of N1a haplogroup

\begin{tabular}{|c|c|c|c|c|c|c|c|}
\hline \multirow[t]{2}{*}{ Clade } & \multirow[t]{2}{*}{ No. of mtDNAs } & \multicolumn{2}{|c|}{ all coding-region base substitutions } & \multicolumn{4}{|c|}{ only synonymous transitions } \\
\hline & & age $^{a}$ & age $^{b}$ & age $^{c}$ & age $^{\text {b }}$ & age $^{d}$ & $\operatorname{age}^{\mathrm{e}}$ \\
\hline N1a & 19 & $23,541 \pm 6,476$ & $21,114 \pm 5,809$ & $19,616 \pm 7,576$ & $22,185 \pm 8,568$ & $22,864 \pm 8,830$ & $23,171 \pm 8,949$ \\
\hline N1a1 & 17 & $18,761 \pm 5,037$ & $16,827 \pm 4,518$ & $13,934 \pm 5,005$ & $15,759 \pm 5,661$ & $16,241 \pm 5,834$ & $16,459 \pm 5,913$ \\
\hline N1a1a1 & 10 & $8,738 \pm 2,570$ & $7,837 \pm 2,305$ & $6,764 \pm 2,841$ & $7,650 \pm 3,213$ & $7,884 \pm 3,311$ & $7,990 \pm 3,356$ \\
\hline N1a1a1a & 3 & $11,976 \pm 5,140$ & $10,741 \pm 4,610$ & $8,996 \pm 5,546$ & $10,175 \pm 6,273$ & $10,486 \pm 6,465$ & $10,627 \pm 6,552$ \\
\hline N1a1a2 & 4 & $5,140 \pm 2,570$ & $4,610 \pm 2,305$ & $3,382 \pm 2,367$ & $3,825 \pm 2,678$ & $3,942 \pm 2,759$ & $3,995 \pm 2,797$ \\
\hline
\end{tabular}

a. - mutation rate of Mishmar et al. [35].

b. - mutation rate of Perego et al. [37].

c. - mutation rate of Kivisild et al. [36].

d. - mutation rate of Soares et al. [38].

e. - mutation rate of Loogvali et al. [39].

\section{Methods}

\section{Samples collection}

We collected about 3,625 blood samples from the South Asia region, including 64 from Nepal; 47 from Bhutan; 160 from Bangladesh and 3,354 from India. All DNA samples analyzed in the present study were derived from the blood samples collected with informed consent according to protocols approved by the Universities of North Bengal, West Bengal, India. We typed the mtDNA control region ( $\mathrm{HV}-1$ and $\mathrm{HV}-2)$ and found three individuals (one from Tamil Nadu-South India and other two from West Bengal-East India) which belonged to the N1a haplogroup. Of these three N1a individuals, two were chosen for complete mtDNA sequences analysis (sample No. 7 and No. 8 in figure 1). To get clear picture of the extent of farmer and published haplogroup N1a diversity, a further ten mtDNAs were chosen for complete sequence analysis. Those samples from Russian Federation (sample No.1- Kazakh, No. 9-Tatar, and No.10 \& No.16 -Russia), No.2-Hungary, No.12-France, No.17-Italy, and No.11, 14, \& 15 the United States of America have a European ancestry. Samples 2, 11, 12, 14, 15 and 17 were selected from the public participant pool through preliminary control region information that was gathered from two websites: Mitosearch http://www.mitosearch.org/ and mtDNA test results log database http://www.kerchner.com/cgi-bin/ mtdna.cgi. We obtained informed consent from each participant to use their data for scientific study.

\section{Complete mtDNA sequencing}

We obtained the complete mtDNA sequences via methods previously reported $[9,29]$. Sequencing was performed on 3130 and 3730 Genetic Analyzers (Applied Biosystems), and the resulting sequences were handled with the SeqScape (v. 2.5-Applied Biosystems) and DNASTAR software (DNASTAR, Inc., Madison, USA). Mutations were scored relative to the revised Cambridge Reference Sequence (rCRS) [30]. The complete mtDNA sequences of sample No. $1,9,10$, and 16 were obtained by Genetics laboratory,
Institute of Biological Problem of the North, Magadan, Russia. The remaining $8 \mathrm{mtDNAs}$ complete sequences were done in the Laboratory for Conservation and Utilization of Bioresources, Yunnan University, Kunming, China. The complete mtDNA sequences reported in this paper have been deposited in GenBank under accession numbers GU123026, GU290206 - GU290216 http://www.ncbi.nlm. nih.gov/Genbank/index.html.

\section{Phylogenetic analysis}

Phylogenetic relationships among the complete mtDNA sequences were established using the reduced median network algorithm http://www.fluxus-engineering.com and the tree was checked manually to resolve homoplasies. In addition to our twelve complete sequences, seven published sequences were added to establish the N1a phylogeny (Figure 1, sample No.3, 4, 5, 18-Accession number EF153778, EF486519, EF486518, EF486517 [9]; No.13-EF657753 [31]; No. 6-EF660937 [32]; and No.19- EF184638 [33], respectively). The tree is rooted in haplogroup $\mathrm{N}$, using the revised Cambridge reference sequence (rCRS) [30] as an outgroup.

\section{Phylogeographic and Coalescence analyses}

To assess the farmer N1a type variation and phylogeographic relationship, we performed a detailed survey of modern published N1a types from West, Central and East European, the Caucasus, the Near East, and West, Central and South Asian groups. A total of 162 (excluded 4 public participants from United States of America) N1a haplotypes were observed and are presented in the table 1. By using a motif recognition and matching and nearmatching strategy with our current N1a subclades phylogeny, all of the published N1a haplotypes were assigned to their respective N1a subhaplogroup. The subclade haplotype heterogeneity was evaluated with chi-square statistics (computer software available from http://www. quantpsy.org). The coalescence times were estimated with $\rho$ statistics (mean divergence from inferred ancestral haplotype), and standard errors $(\sigma)$ were calculated 
following the method of Saillard et al. [34]. Each subclade value of $\rho \pm \sigma$ was converted into time with different calibration rates as described by authors [35-39].

\section{Abbreviations}

LBK: Linearbandkeramik; Sample ID related to archaeological sites-DEB: Derenburg; HAL: Halberstadt; FLO: Flomborn; UWS: Unterwiederstedt; ECS: Ecsegfalva.

\section{Acknowledgments}

We thank two anonymous referees for their valuable comments and Bonnie Schrack for sample collection. Y. P. Z. was supported by the Natural Science Foundation of Yunnan Province, and National Natural Science Foundation of China, M. G. P. was supported by Yunnan University and Yunnan Provincial Science and Technology Department, M.D. was supported by Russian Foundation for Basic Research, and B.M. (Boris Malyarchuk) was supported by the Program of Presidium of Russian Academy of Sciences "Biodiversity (Gene pools and genetic diversity)".

\section{Author details}

'Laboratory for Conservation and Utilization of Bio-resources, Yunnan University, 2 North Green Lake Street, Kunming 650091, China. ${ }^{2}$ State Key Laboratory of Genetic resources and Evolution, Kunming Institute of Zoology, Chinese Academy of Sciences, Kunming 650223, China. ${ }^{3}$ Cellular Immunology Laboratory, Department of Zoology, University of North Bengal, Siliguri 734013, West Bengal, India. ${ }^{4}$ Institute of Biological Problems of the North, Far-East Branch of the Russian Academy of Sciences, Magadan 685000, Russia.

\section{Authors' contributions}

MGP, CLZ, BM, and MD performed laboratory analyses. MGP and YPZ conceived the project. MGP wrote the paper with help of YPZ, MD, TKC and BM (Boris Malyarchuk). All authors read and approved the manuscript.

\section{Competing interests}

The authors declare that they have no competing interests.

\section{Received: 31 March 2010 Accepted: 12 October 2010}

Published: 12 October 2010

\section{References}

1. Ammerman AJ, Cavalli-Sforza LL: The Neolithic Transition and the Genetics of Population in Europe Princeton, NJ: Princeton University Press 1984.

2. Whittle A: Europe in the Neolithic. The creation of New Worlds Cambridge, UK: Cambridge University Press 1996.

3. Haak W, Forster P, Bramanti B, Matsumura S, Brandt G, Tanzer M, Villems R, Renfrew C, Gronenborn D, Alt KW, Burger J: Ancient DNA from the first European farmers in 7500-years-old Neolithic sites. Science 2005, 310(5750):1016-1018

4. Bramanti B, Thomas MG, Haak W, Unterlaender M, Jores P, Tambets K, Antanitis-Jacobs I, Haidle MN, Jankauskas R, Kind CJ, Lueth F, Terberger T, Hiller J, Matsumura S, Forster P, Burger J: Genetic discontinuity between local hunter-gatherers and central Europe's first farmers. Science 2009, 326(5949):137-140.

5. Row-Conwy P: Human prehistory: hunting for the earliest farmers. Curr Biol 2009, 19(20):R948-949.

6. Balter M: Ancient DNA says Europe's first farmers came from afar. Science 2009, 325(5945):1189.

7. Pinhasi R, von Cramon-Taubadel N: Craniometric data supports demic diffusion model for the spread of agriculture into Europe. Plos one 2009, 4(8):e6747.

8. Levy-Coffman E: We are not our ancestors: evidence for discontinuity between prehistoric and modern Europeans. J Genet Geneal 2006, 1:40-50.

9. Derenko M, Malyarchuk B, Grzybowski T, Denisova G, Dambueva I, Perkova M, Dorzhu C, Luzina F, Lee HK, Vanecek T, Villems R, Zakharov I: Phylogeographic analysis of mitochondrial DNA in northern Asian populations. Am J Hum Genet 2007, 81(5):1025-1041.
10. van Oven $M$, Kayser M: Updated comprehensive phylogenetic tree of global human mitochondrial DNA variation. Hum Mutat 2009, 30(2): E386-E394 [http://www.phylotree.org].

11. Hedman M, Brandstätter A, Pimenoff $V$, Sistonen P, Palo JU, Parson W, Sajantila A: Finnish mitochondrial DNA HVS-I and HVS-II population data. Forensic Sci Int 2007, 172(2-3):171-178.

12. Pimenoff VN, Comas D, Palo JU, Vershubsky G, Kozlov A, Sajantila A: Northwest Siberian Khanty and Mansi in the junction of West and East Eurasian gene pools as revealed by uniparental markers. Eur J Hum Genet 2008, 16(10):1254-1264.

13. Nasidze I, Quinque D, Rahmani M, Alemohamad SA, Stoneking M: Concomitant replacement of language and mtDNA in South Caspian populations of Iran. Curr Biol 2006, 16(7):668-673.

14. Lappalainen $T$, Laitinen $V$, Salmela $E$, Anderson P, Huoponen $K$, Savontaus ML, Lahermo P: Migration waves to the Baltic Sea region. Ann Hum Genet 2008, 72(Pt3):337-348.

15. Lehocký I, Baldovic M, Kádasi L, Metspalu E: A database of mitochondrial DNA hypervariable regions I and II sequences of individuals from Slovakia. Forensic Sci Int Genet 2008, 2(4):e53-59.

16. Gokcumen O, Dulik MC, Pai AA, Zhadanov SI, Rubinstein S, Osipova LP, Andreenkov OV, Tabikhanova LE, Gubina MA, Labuda D, Schurr TG: Genetic variation in the enigmatic Altaian Kazakhs of South-Central Russia: insights into Turkic population history. Am J Phys Anthropol 2008, 136(3):278-293.

17. Naumova OY, Rychkov SY, Morozova IY, Khaiat SS, Semikov AV, Zhukova OV: Mitochondrial DNA diversity in Siberian Tatars of the TobolIrtysh basin. Genetika 2008, 44(2):257-268.

18. Naumova OY, Rychkov SY, Zhukova OV: Mitochondrial DNA variability in populations and ethnic groups of Tatars of the Tobol-Irtysh basin. Genetika 2009, 45(9):1260-1269.

19. Grzybowski T, Malyarchuk BA, Derenko MV, Perkova MA, Bednarek J, Woźniak M: Complex interactions of the Eastern and Western Slavic populations with other European groups as revealed by mitochondrial DNA analysis. Forensic Sci Int Genet 2007, 1(2):141-147.

20. Abu-Amero KK, Larruga JM, Cabrera VM, González AM: Mitochondrial DNA structure in the Arabian Peninsula. BMC Evol Biol 2008, 12(8):45.

21. Brandstätter A, Niederstätter $H$, Pavlic M, Grubwieser P, Parson W: Generating population data for the EMPOP database - an overview of the mtDNA sequencing and data evaluation processes considering 273 Austrian control region sequences as example. Forensic Sci Int 2007, 166(2-3):164-175.

22. Gonzalez AM, Brehm A, Perez JA, Maca-Meyer N, Flores C, Cabrera VM: Mitochondrial DNA affinities at the Atlantic fringe of Europe. Am J Phys Anthropol 2003, 120(4):391-404

23. Abu-Amero KK, González AM, Larruga JM, Bosley TM, Cabrera VM: Eurasian and African mitochondrial DNA influences in the Saudi Arabian population. BMC Evol Biol 2007, 1(7):32.

24. Cerny V, Mulligan CJ, Ridl J, Zaloudkova M, Edens CM, Hajek M, Pereira L: Regional differences in the distribution of the sub-Saharan, West Eurasian, and South Asian mtDNA lineages in Yemen. Am J Phys Anthropol 2008, 136(2):128-137.

25. Behar DM, Metspalu E, Kivisild T, Rosset S, Tzur S, Hadid Y, Yudkovsky G, Rosengarten D, Pereira L, Amorim A, Kutuev I, Gurwitz D, Bonne-Tamir B, Villems R, Skorecki K: Counting the founders: the matrilineal genetic ancestry of the Jewish Diaspora. Plos one 2008, 3(4):e2062.

26. Alshamali F, Brandstätter A, Zimmermann B, Parson W: Mitochondrial DNA control region variation in Dubai, United Arab Emirates. Forensic Sci Int Genet 2008, 2(1):e9-10

27. Irwin J, Saunier J, Strouss K, Paintner C, Diegoli T, Sturk K, Kovatsi L, Brandstatter A, Cariolou MA, Parson W, Parsons TJ: Mitochondrial control region sequences from northern Greece and Greek Cypriots. Int J Legal Med 2008, 122(1):87-89.

28. Zvelebil M: The social context of the agricultural transition in Europe. In Archaeogenetics: DNA and the population prehistory of Europe. Edited by: Renfrew C, Boyle K. Cambridge, UK: McDonald Institute; 2000:57-79.

29. Palanichamy MG, Sun C, Agrawal S, Bandelt HJ, Kong QP, Khan F, Wang CY, Chaudhuri TK, Palla V, Zhang YP: Phylogeny of mitochondrial DNA macrohaplogroup $\mathrm{N}$ in India, based on complete sequencing: implications for the peopling of South Asia. Am J Hum Genet 2004, 75(6):966-978. 
30. Andrews RM, Kubacka I, Chinnery PF, Lightowlers RN, Turnbull DM, Howell N: Reanalysis and revision of the Cambridge reference sequence for human mitochondrial DNA. Nat Genet 1999, 23(2):147.

31. Gasparre G, Porcelli AM, Bonora E, Pennisi LF, Toller M, lommarini L, Ghelli A, Moretti M, Betts CM, Martinelli GN, Ceroni AR, Curcio F, Carelli V, Rugolo M, Tallini G, Romeo G: Disruptive mitochondrial DNA mutations in complex I subunits are markers of oncocytic phenotype in thyroid tumors. Proc Natl Acad Sci USA 2007, 104(21):9001-9006.

32. Herrnstadt C, Elson JL, Fahy E, Preston G, Turnbull DM, Anderson C, Ghosh SS, Olefsky JM, Beal MF, Davis RE, Howell N: Reduced-mediannetwork analysis of complete mitochondrial DNA coding-region sequences for the major African, Asian, and European haplogroups. Am J Hum Genet 2002, 70(5):1152-1171.

33. Gonder MK, Mortensen HM, Reed FA, de Sousa A, Tishkoff SA: WholemtDNA genome sequence analysis of ancient African lineages. Mol Biol Evol 2007, 24(3):757-768.

34. Saillard J, Forster P, Lynnerup N, Bandelt HJ, Nørby S: mtDNA variation among Greenland Eskimos: the edge of the Beringian expansion. Am J Hum Genet 2000, 67(3):718-26.

35. Mishmar D, Ruiz-Pesini E, Golik P, Macaulay V, Clark AG, Hosseini S, Brandon M, Easley K, Chen E, Brown MD, Sukernik Rl, Olckers A, Wallace DC: Natural selection shaped regional mtDNA variation in humans. Proc Natl Acad Sci USA 2003, 100(1):171-176.

36. Kivisild T, Shen P, Wall DP, Do B, Sung R, Davis K, Passarino G, Underhill PA, Scharfe C, Torroni A, Scozzari R, Modiano D, Coppa A, de Knijff P, Feldman M, Cavalli-Sforza LL, Oefner PJ: The role of selection in the evolution of human mitochondrial genomes. Genetics 2006, 172(1):373-387.

37. Perego UA, Achilli A, Angerhofer N, Accetturo M, Pala M, Olivieri A, Kashani BH, Ritchie KH, Scozzari R, Kong QP, Myres NM, Salas A, Semino O, Bandelt HJ, Woodward SR, Torroni A: Distinctive Paleo-Indian migration routes from Beringia marked by two rare mtDNA haplogroups. Curr Biol 2009, 19(1):1-8.

38. Soares P, Ermini L, Thomson N, Mormina M, Rito T, Rohl A, Salas A, Oppenheimer S, Macaulay V, Richareds MB: Correcting for purifying selection: an improved human mitochondrial molecular clock. Am J Hum Genet 2009, 84(6):740-759.

39. Loogvali EL, Kivisild T, Margus T, Villems R: Explaining the imperfection of the molecular clock of Hominid mitochondria. PLos one 2009, 4(12):e8260.

doi:10.1186/1471-2148-10-304

Cite this article as: Palanichamy et al:: Mitochondrial haplogroup N1a phylogeography, with implication to the origin of European farmers.

BMC Evolutionary Biology 2010 10:304.

\section{Submit your next manuscript to BioMed Central and take full advantage of:}

- Convenient online submission

- Thorough peer review

- No space constraints or color figure charges

- Immediate publication on acceptance

- Inclusion in PubMed, CAS, Scopus and Google Scholar

- Research which is freely available for redistribution 